\title{
Sensory Evaluation and Proximate Composition of Homemade Complementary Food (HCF), Made Using Milk Combinations of Plant and Animal Origin
}

\author{
Nkereuwem Sunday Etukudoh'1, Essiet Akanimo Gordon'2, Ejinaka Reginald Obiora ${ }^{3}$, \\ Oluwo Fredrick ${ }^{4}$, Obeta M. Uchejeso5, Ocheola Oki Ene Joyce ${ }^{6 *}$ \\ ${ }^{1}$ Department of Haematology, Federal School of Medical Laboratory Science, Jos, Nigeria \\ ${ }^{2}$ Department of Basic Science, Federal School of Medical Laboratory Science, Jos, Nigeria \\ ${ }^{3}$ Department of Parasitology, Federal School of Medical Laboratory Science, Jos, Nigeria \\ ${ }^{4}$ Department of Medical Microbiology, Federal School of Medical Laboratory Science, Jos, Nigeria \\ ${ }^{5}$ Department of Medical Laboratory Management, Federal School of Medical Laboratory Science, Jos, Nigeria \\ ${ }^{6}$ Federal School of Medical Laboratory Science, Jos, Nigeria \\ Email: *katejoshua@yahoo.com
}

How to cite this paper: Etukudoh, N.S., Gordon, E.A., Obiora, E.R., Fredrick, O., Uchejeso, O.M. and Joyce, O.O.E. (2021) Sensory Evaluation and Proximate Composition of Homemade Complementary Food (HCF), Made Using Milk Combinations of Plant and Animal Origin. Food and Nutrition Sciences, 12, 343-351.

https://doi.org/10.4236/fns.2021.124027

Received: December 4, 2020

Accepted: April 5, 2021

Published: April 8, 2021

Copyright $\odot 2021$ by author(s) and Scientific Research Publishing Inc. This work is licensed under the Creative Commons Attribution International License (CC BY 4.0).

http://creativecommons.org/licenses/by/4.0/

\begin{abstract}
Sensory analysis tools are the classic means for guaranteeing sensory quality, assessing acceptability, and recognizing faults in food products. Powerful sensory analysis techniques, were applied to evaluate Homemade Complementary Food (HCF) using milk combination of plant and animal origin. An experimental but descriptive method of research was used with Mubi as the study area. Milk from animal, (cow and goat) as well as milk from plant origin (soya beans milk,) was used. Milk from animal source was pasteurized using Vat pasteurization process (FDA, 2015) while quality soya beans milk was used to prepare milk of plant origin. Blended banana was also used as part of the home made complementary food alongside milk on a 50:50 ratio. A 15 member trained panel made up of mothers with children under the age of 5 years and currently breast feeding were the respondents, a sensory evaluation sheet based on the 9-point hedonic scale was used for scoring. Proximate analysis of sample was done using standard methods, AOAC (2000). Data was analyzed statistically using means and standard deviation. Results showed that sample B4 (a combination of cow, goat, and soya beans milk + blended banana slurry) had the best sensory attributes of appearance (8.00 $\pm 1.32)$, taste $(7.44 \pm 1.01)$ and overall acceptability $(8.00 \pm 1.22)$, while sample
\end{abstract}

*First author: Nkereuwem Sunday Etukudoh; Second author: Essiet Akanimo Gordon, Ejinaka Reginald Obiora, Oluwo Fredrick; Third author: Obeta M. Uchejeso, Ocheola Oki Ene Joyce. 
B5 (goat milk + blended banana slurry) had the best sensory attributes of colour $(8.00 \pm 0.71)$ and aroma $(7.78 \pm 0.83)$. The proximate composition showed that the home made complementary food contained protein above $(10.97 \pm 0.00)$ from complementary food, this is far above the recommended $6.2 \mathrm{~g} /$ day, required for children 23 months and below assuming the child has an average breast milk intake daily, and fat $(2.76 \pm 0.00)$ from complementary foods, was within the recommendation range, required for children age between 9 - 11 months, also assuming the child is on average breast milk intake daily. These results can be of significant benefits in research, and in food processing industries, globally. Further research in other regions is needed to compare the obtained results in terms of its variance.

\section{Keywords}

Sensory, Complementary Food, Milk, Acceptability

\section{Introduction}

The period where an infant changes from a milk-based diet to one made up of a variety of foods and drinks that complement the milk portion of the diet describes Weaning, some renowned documentation has acknowledged that the period between birth and 2 years of age is a critical window to promote health and development and prevent stunting [1]. For this reason, foods consumed during these periods (alongside breast milk) are often called "complementary foods".

The word Complementary foods, also known as "weaning foods" or "baby foods", which most times are interchangeable, facilitate the transition from a liquid diet based on breast milk and/or infant formula, to one which includes solid foods alongside milk based foods/ and or breast milk. This is because studies have shown that insufficient quantities and inadequate quality of complementary foods, together with poor feeding practices and increased rates of infection during this period are direct risk factors for stunting [2] [3].

Interventions that improve complementary feeding, including education on appropriate feeding practices, are among the most effective to reduce stunting during the first 2 years of life [4] [5]. Sometimes complementary foods are given late to the infants as a result; there could be deficiencies of Vitamin A, Vitamin $\mathrm{K}$ and other important micro molecules/nutrients [6]. Complementary foods also influence the mental growth and performance of children. As a result, if interventions to improve complementary feeding practices were scaled up to nearly universal levels, roughly 100,000 under five deaths could be averted each year [2]. The World Health Organization (WHO) and UNICEF recommend that infants begin consuming safe and nutritionally adequate solid, semisolid, or soft foods starting at 6 months of age while continuing to be breastfed until 2 years of age or beyond. Suggested practices include the timely introduction of complementary foods at 6 months of age, satisfactory meal frequency and portions sizes, diversity of diet, appropriate food texture, safe food preparation, storage and 
good hygiene behaviors, and responsiveness to feeding cues [7] [8].

Recipes for high energy nutrient complementary foods have been formulated the world over, but these recipes don't take to consideration the formulation of a Homemade Complementary Food (HCF) using milk combination of plant and animal origin.

According to the World Health Organization (WHO), the core complementary feeding indicators newly developed and/or redefined included: 1) introduction to solid, semisolid, or soft foods, 2) minimum meal frequency (MMF), 3) minimum diet diversity (MDD), and 4) minimum acceptable diet (MAD) [9]. Indicators amenable to population-level assessment for other critical aspects of complementary feeding such as responsive feeding, adequate food texture, portion size food taste, and safe food preparation and storage were not developed as part of this process as they are more multifaceted in term of assessment. An operational manual to support standardized collection and analysis of these new indicators was released in 2010 [10]. Two major survey programmers, the UNICEF-supported Multiple Indicator Cluster Surveys (MICS) and United States Agency for International Development supported Demographic and Health Survey (DHS) included at least some of these new core indicators within their core survey modules as of 2010. Sufficient data for generation of global estimates for three of the new complementary feeding indicators, namely, MMF, MDD, and MAD, only became available in 2016 [11]. As a result, this work put two of these indicators MAD, and MDD to considerations in order to facilitate easy preparation as well as cheap and available recipe ingredient in the local communities.

Globally, and also in many low- and middle-income countries, overweight and obesity are increasing, creating a double burden of malnutrition, which has to be taken into consideration when providing global guidelines on complementary feeding. Global estimates of the prevalence of overweight in children younger than 5 years of age have increased over time going from $4.8 \%$ (31 million) in 1990 to $6.1 \%$ (41 million) in 2014 [12]. A recent study from Indonesia showed an increase in children from 2 to 5 years old being at risk of overweight or being overweight or obese (Body Mass Index [BMI] $-Z$ scores $>+1$ ) from $10.3 \%$ to $16.5 \%$ from 1993 to 2007 [13].

Meanwhile there is consensus that dairy protein has a strong effect on growth [14]. The effect of meat on growth has been examined in several settings in lowand middle-income settings, but only a modest effect was found [15]. The reason could be that dairy protein has a stronger effect on insulin-like growth factor 1, which plays an important role in child growth, compared to protein from meat [14], but no studies made efforts to compare mixed milk blends of plant and animal sources is why this study wants to understand the sensory impact mix milk blends from plant and animal origin has on Homemade Complementary Food (HCF). Hence the objective of this study is: Sensory evaluation and proximate analysis of Homemade Complementary Food (HCF) made using mixed milk combination of plant and animal origin. 


\section{Materials and Method}

Two animals' milk, cow, and goat milk was used, while soya beans milk was used as the milk from plant source. Fresh cow and goat milk was obtained from the cattle market in Mubi Adamawa State using swan water bottle containers, 75 liter bottles each was used for the collection. Regular cream colored Yellow soybeans (Glycine max (L.) were purchased from the Mubi main market.

\subsection{Methods}

\section{Preparation of Soymilk}

Beans of good quality were carefully selected and soaked overnight $12-18 \mathrm{~h}$, at room temperature in ultrapure water. Once soaked, water was discarded and the grains were allowed in water for 15 minutes then, the beans with the hulls were washed thoroughly, under running water rinsed and drained manually using a rubber sieve. To the soaked beans, water was added in (1:3 beans: water ratios), at room temperature $\left(23^{\circ} \mathrm{C}\right)$ and blended with the beans at high speed for 5 min. The resultant slurry was filtered using a pap filter cloth to remove coarse material (usually composed of insoluble fiber material). Thereafter, the isolated soymilk was boiled on a low heat for 15 minutes to destroy trypsin inhibitor for improving flavor and cooled down to room temperature.

\section{Pasteurization of milk from animal source}

The milk which was collected from the animals was separately pasteurized at a heat of about $63^{\circ} \mathrm{C}$ for a period of 30 minutes, this process also known as Vat pasteurization is defined under the Pasteurized Milk Ordinance [15] as the heat treatment of milk at a minimum of $63^{\circ} \mathrm{C}\left(145^{\circ} \mathrm{F}\right)$ for a minimum hold time of 30 min, after which it was allowed to cool. When it was cold, the milk was labeled appropriately as follows; the goat milk, cow milk and soya beans milk where first labeled singly, then a 1:1 proportion preparation of the animal milk plus the plant based milk was made and labeled, as well as the combination of the three milk types in a ratio 1:1:1 was also made. The samples where labeled as follows.

Sample B1: goat milk

Sample B2: cow milk

Sample B3: soya beans milk

Sample B4: goat milk + soya beans milk + cow milk

Sample B5: goat milk + soya beans milk

Sample B6: cow milk + soya beans milk

Proximate composition analysis was carried out on the milk samples. The proximate composition analysis including moisture content, crude protein, crude fat, crude ash, and crude fiber was determined according to approved AOAC (2000) method [16]. Utilizable carbohydrate content was calculated by difference, that is, $100-(\%$ crude protein $+\%$ crude fiber $+\%$ total ash $+\%$ crude fat).

\section{Preparation of the complementary food}

Ripe banana was obtained from the Mubi main market, it was washed and al- 
lowed to completely dry off the water on it, five sizable bananas were pealed and properly blended for about five minutes; the slurry was turned into a transparent rubber container. To each of the milk samples, an equal volume of banana blended slurry was added, and mixed properly giving a 50/50 volume preparation, this made up the home based complementary food, and each sample was placed in a transparent rubber container, and labeled appropriately, preparatory for sensory evaluation.

\subsection{Methodology}

\section{Research design}

The research was experimental but descriptive in nature

\section{Study area}

The study area was Mubi, Adamawa State located in the North eastern part of Nigeria.

\section{Respondents}

The respondents were breast feeding mothers with at least three children and one under the age of five years, (5 yrs) within the environment, Mubi Adamawa State, and a 15 member trained panel was used.

\section{Eligibility criteria}

Sensory test was setup to identify those that can differentiate between sweet, bitter, salty and sour taste using the Duo trio method, as well as identify few colours. Those who passed this training were eligible.

\section{Instrument for data collection}

The hedonic method of scoring was used and a sensory score sheet was made for this purpose. The most common hedonic scale is the nine-point hedonic scale ranging from $1=$ Dislike extremely and $9=$ Like extremely. The hedonic scale assumes that participants' preferences exist on a continuum and that their responses can be categorized into like and dislike [17]. Thus, the scale has ruler-like and equal-interval properties. The nine-point scale is straightforward to use, and it has been widely studied.

\section{Validity and reliability}

Review by experts in this field of study, and statisticians were carried out to ensure face validity. A pilot study was carried out to reduce or make errors as minimal as possible.

\section{Statistical analysis}

Data was analyzed using simple statistics of means and standard deviation.

\section{Results}

Sensory evaluation was carried out on the home based complementary food and the following results were obtained.

\section{Discussion}

The results from Table 1, shows that in terms of appearance the sample B4 had 
the highest value for appearance, with $(8.06 \pm 1.32)$, while sample B3 had the lowest value of $(6.78 \pm 1.99)$ this means that sample B4 has the best attribute of appearance and was liked most by the panelist this could be the result of increased oxidative stability, [18].

Sample B5 had the best colour value $(8.00 \pm 0.71)$, this could be the result of proper homogenization of the complementary food, it has been well documented that homogenization increases the oxidative stability of fluid milk [18]. Furthermore, homogenization enhances sensory attributes in fluid milk and its fluid products, such as color, creaminess, and mouth feel [19] [20].

Still on colour, sample B3 had the lowest value (6.56 \pm 1.94$)$, showing that in terms of colour sample B5 had the best sensory attributes.

The test on the aroma of the samples shows that sample B5 had the best score for aroma $(7.78 \pm 0.83)$ from the panelist, while sample B3 had the lowest score $(6.22 \pm 1.39)$ as we can see from Table 1.

The comparison on taste shows that, sample B4 had the best taste score (7.44 \pm 1.01 ) of all the samples with additional comments of being very creamy. The sensory perception could be heavily influenced by the balance of the home made complementary foods macronutrient components especially from the milk. It is well known that milk fat plays a critical role in the sensory perception of fluid milk. Milk fat is preferred by all consumer segments at varying levels and is considered to be a contributor to creaminess, which is positively correlated with product liking [21] [22], while the taste of sample B1 had the lowest score (6.33 $\pm 1.58)$.

On the overall acceptability, sample B4 had the best acceptability score (8.00 \pm 1.22). While sample B1 had the lowest score $(6.67 \pm 1.22)$.

On the proximate analysis of the complementary foods, the results as seen in Table 2, shows that the protein contents was highest for sample B6 (16.15 \pm $0.00)$ and lowest for B1 $(10.97 \pm 0.00)$. This means that sample B1 can provide the recommended protein content/day for complementary foods, for children within the ages of $12-23$ months. According to recommendation [23], this age group on assumption of average breast milk intake, need $6.2 / \mathrm{gram}$ or $57 \%$ of protein/day from complementary foods.

Considering also the fat content, the result from Table 2 shows that the fat content was highest for sample B6 $(2.76 \pm 0.01)$ and lowest for sample B1 (2.20 \pm 0.00 ). This could mean that the fat content of the complementary foods is capable of sustaining per day, children ages between 6 - 11 months of age assuming that the child is on average breast milk intake. According to [23] children ages 6 - 8 months require $0 \mathrm{~g} /$ day of fat from complementary foods, and those between ages 9 - 11 months require $3 \mathrm{~g} /$ day or $5 \%-8 \%$ of fat from complementary foods assuming also, average breast milk intake.

The results of the fibre contents shows that the highest fiber content was found in sample B5 with $(0.46 \pm 0.01)$ and the lowest was found in sample B1 $(0.20 \pm$ 0.00 ) but the fibre content is shown to be higher than WHO recommendation of $\leq 5 \%$ on a general note [23]. 
Table 1. A table showing the results of the sensory evaluation of home based complementary food made from mixed milk blend of plant and animal origin.

\begin{tabular}{ccccccc}
\hline & B1 & B2 & B3 & B4 & B5 & B6 \\
\hline APPEARANCE & $6.87 \pm 1.87$ & $7.44 \pm 1.01$ & $6.78 \pm 1.99$ & $8.00 \pm 1.32$ & $7.89 \pm 1.05$ & $6.67 \pm 1.00$ \\
COLOUR & $7.11 \pm 1.69$ & $7.56 \pm 1.01$ & $6.56 \pm 1.94$ & $7.56 \pm 1.13$ & $8.00 \pm 0.71$ & $7.11 \pm 1.05$ \\
AROMA & $7.44 \pm 1.01$ & $7.56 \pm 1.01$ & $6.22 \pm 1.39$ & $7.33 \pm 0.87$ & $7.78 \pm 0.83$ & $6.89 \pm 1.05$ \\
TASTE & $6.33 \pm 1.58$ & $7.33 \pm 1.41$ & $6.89 \pm 1.62$ & $7.44 \pm 1.01$ & $7.11 \pm 0.06$ & $7.33 \pm 1.12$ \\
OVERALL & $6.67 \pm 1.22$ & $7.44 \pm 0.88$ & $7.11 \pm 1.17$ & $8.00 \pm 1.22$ & $7.67 \pm 1.00$ & $7.78 \pm 1.56$ \\
ACCEPTABILTY & & & & & & \\
\hline
\end{tabular}

Key: B1 = Goat Milk +Banana Blend; B2 = Cow Milk + Banana Blend; B3 = Soya Beans Milk + Banana Blend; B4 = Goat + Cow + Soya Milk + Banana Blend; B5 = Goat + Soya + Banana Blend; B6 = Cow + Soya Milk Banana Blend; ${ }^{\star}$ all the milk used was pasteurized using standard procedure.

Table 2. Proximate Results for the complementary food made from the mix milk blend.

\begin{tabular}{|c|c|c|c|c|c|c|}
\hline Samples & PROTEIN & FAT & FIBRE & ASH & MOISTURE & CARBOHYDRATES \\
\hline $\mathrm{B} 1$ & $10.97 \pm 0.00$ & $2.20 \pm 0.00$ & $0.20 \pm 0.00$ & $5.40 \pm 0.01$ & $65.30 \pm 0.00$ & $15.92 \pm 0.00$ \\
\hline B2 & $11.70 \pm 0.00$ & $2.21 \pm 0.01$ & $0.20 \pm 0.00$ & $5.45 \pm 0.00$ & $63.48 \pm 0.00$ & $16.96 \pm 0.02$ \\
\hline B3 & $12.05 \pm 0.01$ & $2.70 \pm 0.00$ & $0.20 \pm 0.00$ & $5.43 \pm 0.01$ & $63.00 \pm 0.00$ & $16.62 \pm 0.02$ \\
\hline B4 & $13.00 \pm 0.00$ & $2.50 \pm 0.00$ & $0.45 \pm 0.01$ & $7.50 \pm 0.00$ & $62.50 \pm 0.00$ & $15.71 \pm 0.02$ \\
\hline B5 & $14.16 \pm 0.01$ & $2.54 \pm 0.01$ & $0.47 \pm 0.01$ & $7.50 \pm 0.00$ & $61.25 \pm 0.00$ & $15.19 \pm 0.02$ \\
\hline B6 & $16.15 \pm 0.00$ & $2.76 \pm 0.01$ & $0.46 \pm 0.01$ & $7.50 \pm 0.00$ & $59.75 \pm 0.00$ & $13.39 \pm 0.00$ \\
\hline
\end{tabular}

Three samples, B4, B5, B6, had the highest ash contents, of $(7.50 \pm 0.00)$ and the ash content is an indicator of the quantity of minerals in the food [24].

Considering moisture contents, the result in Table 2 shows that, moisture contents was lowest for sample B6 (59.75 \pm 0.00) and highest for sample B1 (65.30 \pm 0.00). Apart from helping to determine the shelf life of products, moisture content helps to know the water activity, and hence the microbial effects on foods.

\section{Conclusion}

Sample B4 had the best sensory attributes of appearance and taste as well as over all acceptability. And sample B5 had the best sensory attributes of colour, as well as aroma. These combinations can be adopted by food industries to take complementary foods to the next level especially homemade complimentary food, while the proximate composition shows prospects for protein and fat as well as ash (mineral) content.

\section{Recommendation}

1) This recipe of homemade complementary foods should be replicated in other regions to understand the variance in its sensory evaluation.

2) More research is required on this recipe to understand apart from other things its energy content 


\section{Conflicts of Interest}

The authors declare no conflicts of interest regarding the publication of this paper.

\section{References}

[1] de Onis, M. and Branca, F. (2016) Childhood Stunting: A Global Perspective. Maternal \& Child Nutrition, 12, 12-26. https://doi.org/10.1111/mcn.12231

[2] Bhutta, Z.A., Das, J.K., Rizvi, A., Gaffey, M.F., Walker, N., Horton, S., et al. (2013) Evidence-Based Intervention for Improving Maternal and Child Nutrition: What Can Be Done and at What Cost? The Lancet, 382, 452-477. https://doi.org/10.1016/S0140-6736(13)60996-4

[3] Danaei, G., Andrews, K.G., Sudfeld, C.R., Fink, G., McCoy, D.C., Peet, E., Fawzi, W.W., et al. (2016) Risk Factors for Childhood Stunting in 137 Developing Countries: A Comparative Risk Assessment Analysis at Global, Regional, and Country Levels. PLoS Medicine, 13, e1002164. https://doi.org/10.1371/journal.pmed.1002164

[4] Black, R.E., Allen, L.H., Bhutta, Z.A., Caulfield, L.E., de Onis, M., Ezzati, M. and Child Undernutrition Study G. (2008) Maternal and Child Undernutrition: Global and Regional Exposures and Health Consequences. The Lancet, 371, 243-260. https://doi.org/10.1016/S0140-6736(07)61690-0

[5] Dewey, K.G. and Adu Afarwuah, S. (2008) Systematic Review of the Efficacy and Effectiveness of Complementary Feeding Interventions in Developing Countries. Maternal \& Child Nutrition, 4, 24-85. https://doi.org/10.1111/j.1740-8709.2007.00124.x

[6] Alvisi, P., et al. (2015) Recommendations on Complementary Feeding for Healthy, Full-Term Infants. Italian Journal of Pediatrics, 41, Article No. 36. https://doi.org/10.1186/s13052-015-0143-5

[7] White, J.M., Bégin, F., Kumapley, R., Murray, C. and Krasevec, J. (2017) Complementary Feeding Practices: Current Global and Regional Estimates. Maternal and Child Nutrition, 13, e12505. https://doi.org/10.1111/mcn.12505

[8] WHO \& UNICEF (2003) Global Strategy for Infant and Young Child Feeding. World Health Organization, Geneva.

[9] WHO (2008) Indicators for Assessing Infant and Young Child Feeding Practices: Part 1: Definitions. World Health Organization, Geneva.

[10] WHO (2010) Indicators for Assessing Infant and Young Child Feeding Practices: Part 2: Measurement. World Health Organization, Geneva.

[11] UNICEF, WHO and World Bank (2016) Joint Malnutrition Estimates-Levels and Trends, 2016 Edition.

[12] UNICEF, WHO, World Bank Group (2015) Levels and Trends in Child Malnutrition. UNICEF-WHO-World Bank Group Joint Child Malnutrition Estimates. Key Findings of the 2015 Edition.

[13] Rachmi, C.N., Agho, K.E., Li, M. and Baur, L.A. (2016) Stunting, Underweight and Overweight in Children Aged 2.0-4.9 Years in Indonesia: Prevalence Trends and Associated Risk Factors. PLoS ONE, 11, e0154756.

https://doi.org/10.1371/journal.pone.0154756

[14] Michaelsen, K.F., Grummer-Strawn, L. and Bégin, F. (2017) Emerging Issues in Complementary Feeding: Global Aspects. Maternal \& Child Nutrition, 13, e12444. https://doi.org/10.1111/mcn.12444

[15] Krebs, N.F., Mazariegos, M., Chomba, E., Sami, N., Pasha, O., Tshefu, A. and Ham- 
bidge, K.M. (2012) Randomized Controlled Trial of Meat Compared with Multimicronutrient-Fortified Cereal in Infants and Toddlers with High Stunting Rates in Diverse Settings. American Journal of Clinical Nutrition, 96, 840-847.

https://doi.org/10.3945/ajcn.112.041962

[16] AOAC (2000) Association of Official Analytical Chemists. Official Methods of Analysis. Vol. II, 17th Edition, AOAC, Washington DC.

[17] Lawless, H.T. and Heymann, H. (2010) Sensory Evaluation of Food: Principles and Practices. Springer, New York. https://doi.org/10.1007/978-1-4419-6488-5

[18] Zahar, M., Smith, D.E. and Warthesen, J.J. (1986) Effect of Carrier Type and Amount on Vitamin A Light Degradation in Fortified Low Fat and Skim Milks. Journal of Dairy Science, 69, 2038-2044. https://doi.org/10.3168/jds.S0022-0302(86)80634-8

[19] Richardson, N.J., Booth, D.A. and Stanley, N.L. (1993) Effect of Homogenization and Fat Content on Oral Perception of Low and High Viscosity Model Creams. Journal of Sensory Studies, 8, 133-143. https://doi.org/10.1111/j.1745-459X.1993.tb00208.x

[20] Feng, H., Barbosa-Cánovas, G.V. and Weiss, J. (2011) Ultrasound Technologies for Food and Bioprocessing. Vol. 1, Springer, New York.

https://doi.org/10.1007/978-1-4419-7472-3

[21] Richardson-Harman, N.J., Stevens, R., Walker, S., Gamble, J., Miller, M. and McPherson, A. (2000) Mapping Consumer Perceptions of Creaminess and Liking for Liquid Dairy Products. Food Quality and Preference, 11, 239-246.

https://doi.org/10.1016/S0950-3293(99)00060-9

[22] McCarthy, K.S., Lopetcharat, K. and Drake, M.A. (2017) Milk Fat Threshold Determination and the Effect of Milk Fat Content on Consumer Preference for Fluid Milk. Journal of Dairy Science, 100, 1702-1711. https://doi.org/10.3168/jds.2016-11417

[23] Abeshu, M.A., Lelisa, A. and Geleta, B. (2016) Complementary Feeding: Review of Recommendations, Feeding Practices, and Adequacy of Homemade Complementary Food Preparations in Developing Countries-Lessons from Ethiopia. Frontiers in Nutrition, 3, 41. https://doi.org/10.3389/fnut.2016.00041

[24] http://www.dairyfoods.com 